\title{
Epidemiological Aspects of Malaria in Pregnant Women: Prevalence and Risk Factors in Mwene Ditu, DR Congo
}

\author{
Musasa Kasongo Jean-Claude', Mwarabu Much'apa Bienfait ${ }^{2}$, Ilunga Kandolo Simon ${ }^{2 *}$, \\ Kakoma Sakatolo Zambeze Jean-Baptiste ${ }^{2,3}$ \\ ${ }^{1}$ Faculty of Medicine, University of Mwene Ditu, Mwene Ditu, Democratic Republic of Congo \\ ${ }^{2}$ School of Public Health, University of Lubumbashi, Lubumbashi, Democratic Republic of Congo \\ ${ }^{3}$ Faculty of Medicine, University of Lubumbashi, Lubumbashi, Democratic Republic of Congo \\ Email: ^silungak@gmail.com
}

How to cite this paper: Jean-Claude, M.K., Bienfait, M.M., Simon, I.K. and Jean-Baptiste, K.S.Z. (2018) Epidemiological Aspects of Malaria in Pregnant Women: Prevalence and Risk Factors in Mwene Ditu, DR Congo. Open Access Library Journal, 5: e4676. https://doi.org/10.4236/oalib.1104676

Received: May 23, 2018

Accepted: June 23, 2018

Published: June 26, 2018

Copyright () 2018 by authors and Open Access Library Inc.

This work is licensed under the Creative Commons Attribution International License (CC BY 4.0).

http://creativecommons.org/licenses/by/4.0/

\begin{abstract}
Introduction: Malaria in pregnancy induces significant risks for the mother and the foetus. The objective of this study was to determine the prevalence of malaria and the risk factors among pregnant women in the Health District of Mwene Ditu in DR Congo.Methods: A cross-sectional descriptive study based on household survey was carried out in June 2016 in the Health District of Mwene Ditu. The calculated sample size was 461 pregnant women selected through a stratified random sampling. A structured interview using a pre-established questionnaire was administered to and peripheral blood samples were collected for laboratory tests in all pregnant women presenting malaria symptoms or fever history. The following statistics were used: Chi square test and Odds ratio with a confidence interval at $95 \%$.Results The prevalence of malaria in pregnant women was $14.97 \%$. The following parameters proved to be risk factors for malaria illness in pregnant women in Mwene Ditu: low socio-economic level of the couple $[\mathrm{AOR}=6.48(1.51 ; 27.78)]$, agrarian activities $[\mathrm{AOR}=5,56(2.47 ; 12.50)]$, facts of not sleeping under ITBN each night $[\mathrm{AOR}=17.39(8.38 ; 36.10)]$ as well as of not getting SP for intermittent preventive treatment $(\mathrm{IPT})$ in pregnancy $[\mathrm{AOR}=4.08(1.32 ; 12.59)]$ and financially supporting all interventions for fighting against malaria $[\mathrm{AOR}=3.43$ $(1.42 ; 8.29)]$. Conclusion: Malaria is frequent among the pregnant women of Mwene Ditu. The ANC frequentation and an appropriate organization prove to be paramount interest.
\end{abstract}

\section{Subject Areas}

Epidemiology, Public Health 


\section{Keywords}

Epidemiological Aspects, Malaria, Pregnant Women Risk Factors, Mwene Ditu, DR Congo

\section{Introduction}

Malaria remains a major public health problem in the world. In 2015, there were 3.2 billion people still at risk of malaria infection, resulting in 214 million cases and 438,000 deaths worldwide. Countries in sub-Saharan Africa bear the brunt of the disease, including Nigeria and the Democratic Republic of Congo (DRC) alone, with more than $35 \%$ of deaths from malaria worldwide. Children and women are the most exposed [1]. Pregnant women are at high risk of Plasmodium falciparum infection with serious and multiple complications, including placental malaria, fever, maternal anemia, termination of pregnancy, fetal exposure to the parasite Congenital infection, low birth weight, intrauterine growth retardation (IUGR) and infant mortality with anemia [2]-[8]. A Ghanaian study found that pregnant women had $42.6 \%$ and $56.4 \%$ malaria prevalence in two different settings [9]. According to a Nigerian study conducted by Fana et al. [10], the low level of education and lack of use of the insecticide-treated net (ITN) was significantly associated with malaria infection during pregnancy.

In the Democratic Republic of Congo, the year 2013 recorded 11,363,817 malaria cases (38\% of external consultations), 955,311 cases of severe malaria (in hospitalization) and 30,918 deaths, i.e. 39\% of hospital deaths [11]. According to the DHS-DRC [12], the prevalence of malaria based on microscopic examination of the thick film is $23 \%$ in children aged 6 to 59 months. Malaria prevalence is increasing significantly among HIV-positive pregnant women, as shown by a study that found a prevalence of malaria of $74.1 \%$ among pregnant women living with HIV in Kinshasa [13]. Despite the trend reversal of malaria incidence at the global, African and national levels, the Mwene Ditu Health Districts, part of Lomami Province with a parasite prevalence rate ranging from $31 \%$ to 55\% [14], continues to record high proportions of malaria among pregnant women, i.e. $35 \%$ of pregnant women with malaria in 2015 among those received at antenatal care (ANC). Thus, the present study aims to assess the prevalence of malaria infection and the associated risk factors among pregnant women in the city of Mwene Ditu.

\section{Methodology}

Our study was conducted in the Democratic Republic of Congo, in the city of Mwene Ditu, specifically in the Mwene Ditu Health district, part of the Provincial Division of Lomami in Lomami Province. The Mwene Ditu Health districtis made up of 23 Health Districtss (all functional) of which 20 are located in the city of Mwene Ditu and 3 in the Luilu territory. The Mwene Ditu health district 
has an area of $500 \mathrm{~km}^{2}$ and an estimated population of 441,480 inhabitants in 2016, a density of 883 inhabitants per $\mathrm{km}^{2}$. The Province of Lomami is classified as Strate III, i.e. hyper-endemic zone with parasite prevalence rate between 31 and $55 \%$ [14].

Type of study and period of study: This is a cross-sectional descriptive study that ran from June 1 to June 30, 2016. The data collection was done prospectively.

\section{Study Population}

The population of our study consisted of pregnant women from the Mwene Ditu Health Districts.

We performed stratified random sampling. Stratification was done on the basis of residence. The calculated size of our sample was 461 cases

We conducted a household survey and data collection was done by interview using a pre-established questionnaire. Peripheral blood samples were collected for laboratory tests (TDR, G.E and thin smear) in all pregnant women with malaria symptoms or history of fever.

The collected data was captured, encoded and analyzed using Excel 2007 and Epi Info version 7.1.4.0.

The following statistical tests were used to compare the observed proportions, to estimate the association between the dependent variable and the independent variables and to identify the determinants of malaria: Chi-square, Odds Ratio (with a 95\% confidence interval), and logistic regression, the significance level being set at $\mathrm{p}<0.05$

\section{Results}

The prevalence of malaria in our study in pregnant women in the city of Mwene was $14.97 \%$ (95\% CI, 11.90, 18.63) (Table 1). Sociodemographic characteristics of respondents: Pregnant women aged 20 to $34(79.83 \%)$ were the most represented and those aged 19 or over (8.89\%) the least represented. The average age was $27 \pm 6$ years, the extremes being 17 and 43 years old. There were $32.32 \%$ of pauciparas and $6.72 \%$ of large multiparas. Most respondents were married women $(97.83 \%)$. Households of 5 to 6 people, as a whole, represented $31.02 \%$ compared to $10.20 \%$ of households with 1 to 2 persons. The average household size was $6 \pm 2$ people (range: 2 to 13 people). As for the occupation and level of education of the respondents, the majority (51.6\%) and almost half (47.94\%) were housewives and primary school teachers respectively (Figure 1 and Figure 2). Sociodemographic Characteristics of Pregnant and Malaria-Sickness: Pregnant women under the age of 19 had a higher prevalence of malaria-malaria than other age groups, but the difference was not statistically significant. The same was true for pregnant women living in houses made of straw and non-durable materials compared to their counterparts living in houses made of durable materials (Table 2). It was also observed that pregnant women living in 
Table 1. Distribution of pregnant women surveyed by malaria prevalence.

\begin{tabular}{ccc}
\hline Malaria & Frequency & Percentage (\%) \\
\hline NO & 392 & 85,03 \\
YES & 69 & 14,97 \\
Total & 461 & 100,00 \\
\hline
\end{tabular}

Table 2. Socio-demographic characteristics and malaria.

\begin{tabular}{|c|c|c|c|c|c|c|c|c|c|}
\hline \multirow{2}{*}{\multicolumn{2}{|c|}{$\begin{array}{l}\text { Age groups } \\
\text { (years) }\end{array}$}} & \multicolumn{3}{|c|}{ Malaria } & \multirow{2}{*}{ Total } & \multirow{2}{*}{ AOR } & \multirow{2}{*}{ CI $95 \%$} & \multirow{2}{*}{ Chi-square } & \multirow{2}{*}{$\mathrm{p}$} \\
\hline & & Yes & \multicolumn{2}{|c|}{ NO } & & & & & \\
\hline \multicolumn{2}{|l|}{$\leq 19$} & $7(17.07)$ & \multicolumn{2}{|c|}{$34(84.62)$} & 41 & 1.36 & {$[0.60 ; 3.11]$} & 0.27 & 0.6 \\
\hline \multicolumn{2}{|l|}{20 to 34} & $54(14.67)$ & \multicolumn{2}{|c|}{$314(85.33)$} & 368 & 1 & & & \\
\hline \multicolumn{2}{|l|}{$\geq 35$} & $8(15.38)$ & \multicolumn{2}{|c|}{$44(84.62)$} & 52 & 1.05 & {$[0.47 ; 2.36]$} & 0.0054 & 0.94 \\
\hline \multicolumn{2}{|l|}{ Total } & $69(14.97)$ & \multicolumn{2}{|c|}{$392(85.03)$} & 461 & & & & \\
\hline \multirow{2}{*}{\multicolumn{2}{|c|}{ Residence }} & \multicolumn{3}{|c|}{ Malaria } & $T-1$ & & & $C$. & \\
\hline & & Yes & \multicolumn{2}{|c|}{ No } & 10 tal & AUK & C195\% & Cni-square & $\mathrm{p}$ \\
\hline \multicolumn{2}{|c|}{ Urban environment } & $31(14.09)$ & \multicolumn{2}{|c|}{$189(85.91)$} & 220 & 1.31 & {$[0.48 ; 3.58]$} & 0.39 & 0.81 \\
\hline \multicolumn{2}{|c|}{$\begin{array}{l}\text { Peri-urban } \\
\text { environment }\end{array}$} & $33(16.84)$ & \multicolumn{2}{|c|}{$163(83.16)$} & 196 & 1.61 & {$[0.59 ; 4.41]$} & 0.23 & 0.49 \\
\hline \multicolumn{2}{|c|}{ Rural environment } & $5(11.11)$ & 40( & 8.89) & 45 & 1 & & & \\
\hline TOTAL & & 69 & & 2 & 461 & & & & \\
\hline & & Malaria & & & & & & & \\
\hline Housing type & $\mathrm{Ou}$ & No & & Total & & OR & CI95\% & -square & $\mathrm{p}$ \\
\hline Straw house & $18(13$ & $3.43) 116(86$ & $.57)$ & 134 & & 56 & $0.43 ; 28.08]$ & 0.89 & .31 \\
\hline $\begin{array}{l}\text { House made of } \\
\text { non-durable } \\
\text { materials with } \\
\text { sheets }\end{array}$ & $50(16$ & $6.50) 253(83$ & $.50)$ & 303 & & 54 & $\begin{array}{l}{[0.60} \\
34.43]\end{array}$ & 1.71 & .14 \\
\hline $\begin{array}{l}\text { House made of } \\
\text { sustainable } \\
\text { materials }\end{array}$ & $1(4.1$ & $23(95$ & 83) & 24 & & 1 & & & \\
\hline TOTAL & & 69 & & 22 & 461 & & & & \\
\hline M. & & $\mathrm{Mal}$ & aria & & $T$ & ר & & 1. & \\
\hline & & Yes & $\mathbf{N}$ & & & & & & P \\
\hline Single & & $4(40.00)$ & $6(60$ & 00) & 10 & 3.95 & {$[1.08 ; 14.4]$} & 5.02 & 0.025 \\
\hline Married & & $65(14.41)$ & $386(\varepsilon$ & 5.59) & 451 & 1 & & & \\
\hline Total & & 69 & 39 & & 461 & & & & \\
\hline
\end{tabular}

peri-urban areas (16.84\%) had a higher prevalence than those living in urban areas (around $14.09 \%$ ) and rural areas (11.11\%), but without any significant difference. In contrast, the prevalence of malaria in unmarried pregnant women 


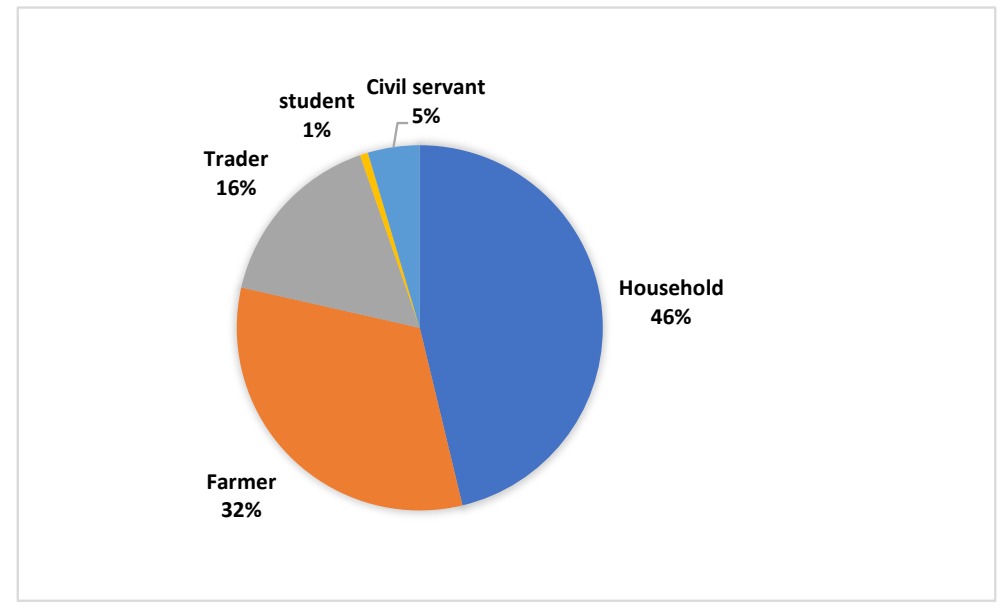

Figure 1. Distribution of pregnant women surveyed by occupation.

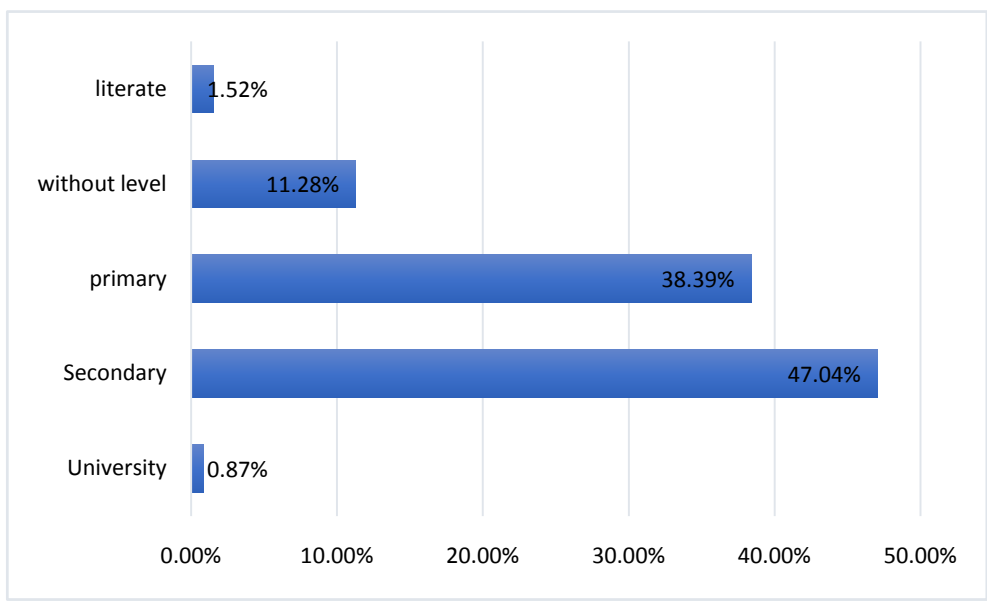

Figure 2. Distribution of pregnant women surveyed by education level.

was higher at $40.00 \%$ compared to $14.41 \%$ among married gestants with a statistically significant difference (Table 2). Households of 7 to 8 people also had more cases of malaria-illness than those of 1 to 2 people $(16 / 98=16.33 \%$ vs. $6 / 47$ $=12.77 \%$ ) and all other sizes.

However, all the differences observed were not significant $(\mathrm{p}=0.9554)$. Pregnant women at the primary level had a high prevalence with 31 out of 177 cases, or $17.15 \%$, followed by high school prevalence (34 out of 221 cases, i.e. $15.38 \%$ ). We did not note any cases of malaria among upper-level pregnant and literate people. No statistically significant association $(\mathrm{P}=0.2841)$ was observed between Pregnant Education Level and Malaria-Malaria (Figure 3 and Figure 4).

Pauciparas had higher malaria prevalence than large multiparas, but the difference was not statistically significant, while pregnant women who did not follow ANC had a high prevalence of malaria, 25.61\%. against $12.66 \%$ for pregnant women who have followed ANC. Pregnant women who did not attend ANC had more than twice the risk of contracting malaria compared to those who did (Table 3). 


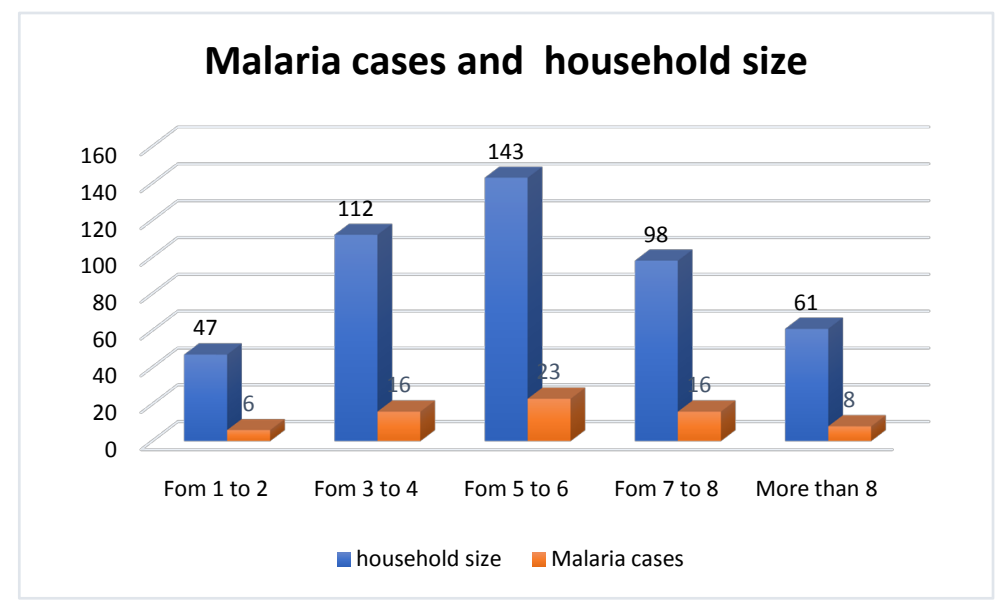

Figure 3. Distribution of malaria cases by household size.

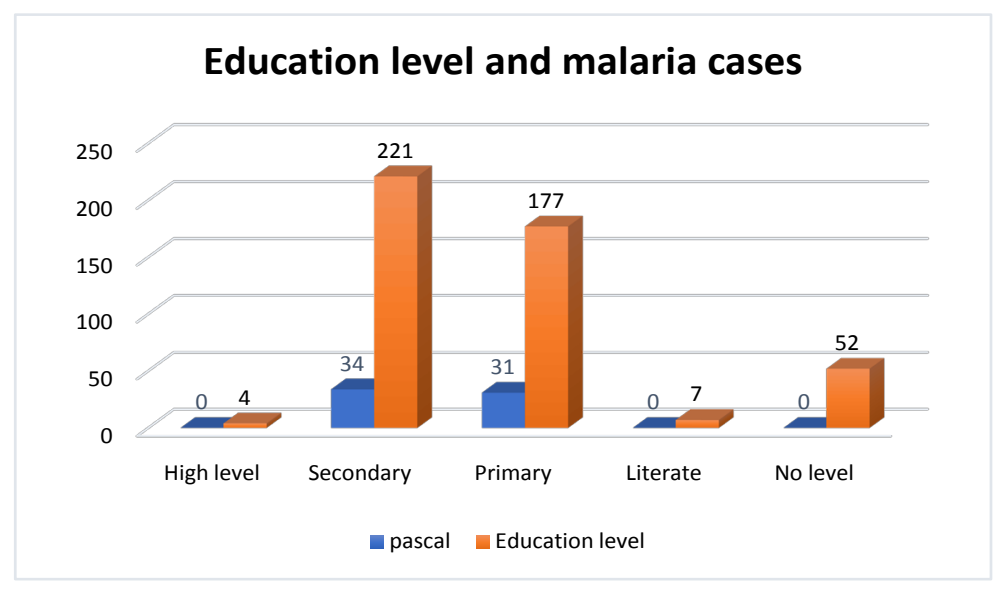

Figure 4. Distribution of respondents according to the association between their level of education and malaria.

In view of the data from the logistic regression, the following risk factors for malaria in pregnant women in the city of Mwene Ditu were selected: Not sleeping under ITNs every night: $\mathrm{AOR}=17.39(95 \% \mathrm{CI}=[8.38,36.10])$, the use of ITN every night being a protective factor: $\mathrm{AOR}=0.05(95 \% \mathrm{CI}=[0.02,0.11])$ but $\mathrm{OR}=19.79(95 \% \mathrm{CI}=[10.65,36.77])(\mathrm{p}<0.001)$ before logistic regression; The low socio-economic level of the couple: AOR $=6.48$ (IC.95\% $=[1.51$, 27.78]), the average socioeconomic level being a protective factor: $\mathrm{AOR}=0.15$ $(95 \% \mathrm{CI}) \%=[0.03,0.66])$ but $\mathrm{OR}=3.74(95 \% \mathrm{CI}=[1.14,12.31]),(\mathrm{p}=0.018)$ before logistic regression; The farming profession: AOR $=5.56$ (IC.95\% $=[2.47$, 12.50]), being housewife being a protective factor: $\mathrm{AOR}=0.17(95 \% \mathrm{CI})=[0.08$, $0.40])$ but $\mathrm{OR}=7.02(95 \% \mathrm{CI}=[3.71,13.27])(\mathrm{p}<0.000001)$ before logistic regression; Not receiving MS for IPT in pregnancy: $\mathrm{AOR}=4.08(95 \% \mathrm{CI}=[1.32$; $12.59])$ but $\mathrm{OR}=3.09(95 \% \mathrm{CI}=[1,81,5.29])(\mathrm{p}=0.00003)$ before logistic regression; Paying or financially supporting malaria interventions: $\mathrm{AOR}=3.43$ $(\mathrm{OR} .95 \%=[1.42 ; 8.29]) \mathrm{OR}=3.79(95 \% \mathrm{CI}=[1,82,7.86])(\mathrm{p}=0.0002)$ before logistic regression. 
Table 3. Obstetrical characteristics and malaria.

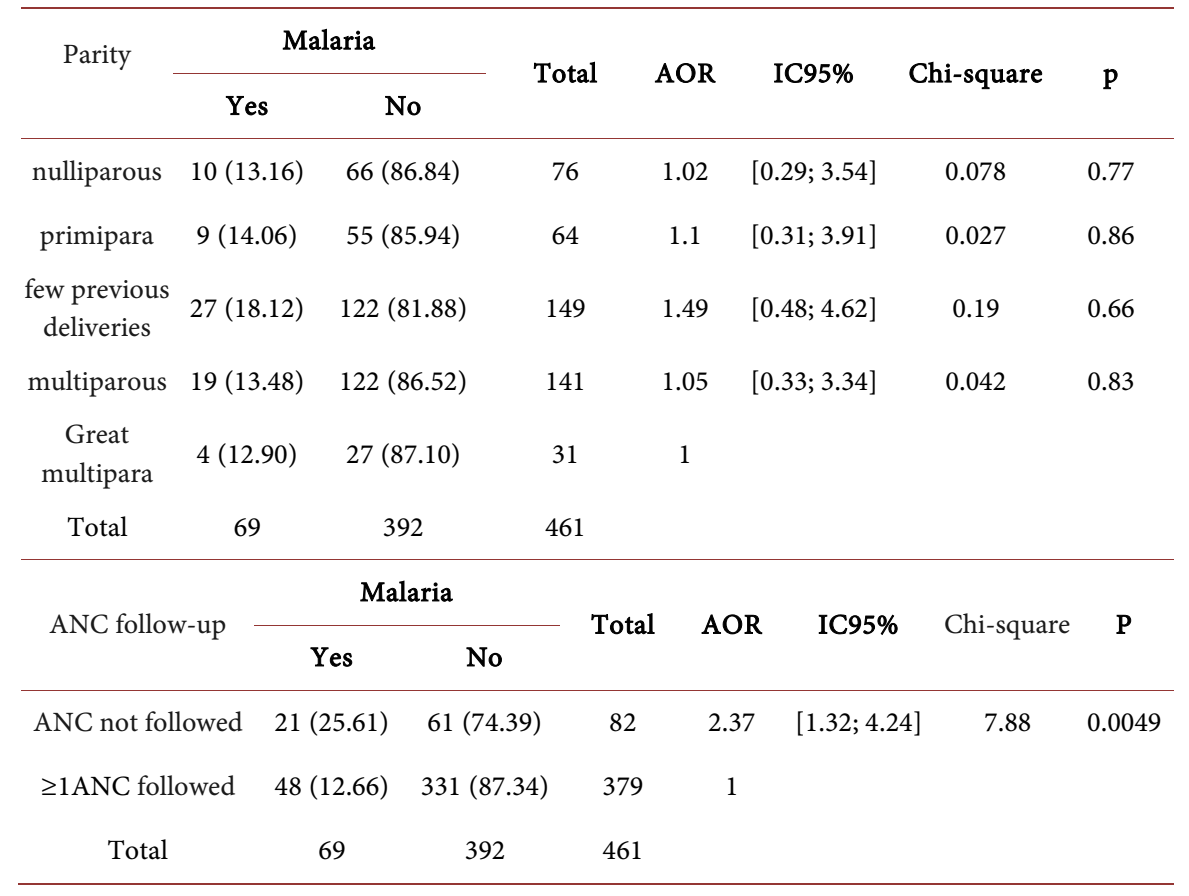

\section{Discussion}

The prevalence of malaria in pregnant women in the city of Mwene Ditu was about $14.97 \%$ (95\% CI: $11.90,18.63)$. This result is similar to those of two studies conducted in Burkina-Faso by the teams of Cissé [3] and Ouédraogo [15] who respectively found a prevalence of malaria on pregnancy of $18.2 \%$ and $18.6 \%$. On the other hand, the difference is clearly observed with the results of various other authors: $42.6 \%$ and $56.4 \%$ respectively for Dako-Gueke and Kofie [9] in two different environments in Ghana as well as $42.6 \%$ for Tahita and collaborators [16] in Burkina Faso and $41.6 \%$ for Fana and allies (10] in Nigeria. It is the same, but to a lesser extent, for the following results: $22.4 \%$ and $22.9 \%$ respectively for Anchang-Kimbi and collaborators [17] as well as for Tonga and collaborators [18] in two different regions of the world. Cameroon. However, a prevalence of 9.1\% which is significantly lower than that of our series was reported by Dræbel and Allies [19] in South Sudan. Discrepancies with higher prevalence than our series may be justified by seasonal fluctuations in malaria access, our survey being conducted during the dry season, which is a period of low transmission. In fact, the absence of rainfall reduces the number of larval sites and consequently leads to a decrease in the Anopheles population, with corollary the fall in malaria cases.

In this study, the age group of pregnant women younger than 20 had a high prevalence of malaria, $17.07 \%$ versus $14.67 \%$ in pregnant women aged $20-34$, but with no significant difference in statistic with other age groups $(p>0.05]$. This prevalence is almost similar to that of a Cameroonian study that found a high prevalence in this same age group, 20\% [17]. The same is true for the re- 
sults reported by Orish et al. [20] who found that pregnant girls in Ghana were more likely to be infected with malaria than adult women $(\mathrm{AOR}=1.65 ;=0.046)$. This could be explained by the lack of specific immunity to placental malaria that is acquired following exposure to malaria parasites during pregnancy [21]. Thus, parity increases with age in our environment, repeated exposure to plasmodium induces the acquisition of this immunity against Plasmodium.

Pauciparas had a high prevalence of $18.12 \%$ compared with $12.90 \%$ in multiparas, but no significant association between parity and occurrence of malaria ( $p>0.05)$. These results are consistent with those of several authors [3] [7] [22] [23] who believe that parity (first and second pregnancy) constitutes a risk factor for malaria. This is explained by the fact that primigests are less frequently exposed to antibodies to chondroitin sulfate A (CSA] [24]. This immunity accumulates during successive pregnancies following exposure to Plasmodium infection [25]. This susceptibility, which is maximal during the first pregnancy, decreases during subsequent pregnancies. Various studies have already shown that this effect is mainly dependent on parity rather than age, even though these two variables are highly linked in the intertropical zones [26]. Women farmers were 6 times more likely to contract malaria than housewives ( $\mathrm{AOR}=5.56, \mathrm{p}<0.001$ ). In contrast, Bashar et al. [27] found a significant association between malaria and house ownership in Bangladesh $(\mathrm{p}<0.01)$. People who spent enough time outdoors in the evening to keep animals were more likely to get malaria than those who did not have pets. Our results could be explained by the fact that.

Pregnant women who are farmers spend enough time or an extended stay in the fields to return to the city that weekend to ensure their supplies. During their stay around gallery forests where the land is fertile and conducive to rural activities, they are exposed to the bites of vectors of malaria for lack of use of ITN. Pregnant women at the primary level had the highest prevalence at $17.15 \%$ compared with $15.38 \%$ for high school and $0 \%$ for university students. This is similar to a study conducted in Nigeria by Fana et al. [10] who found a significant association between malaria prevalence and education $(\mathrm{X} 2=20.9, \mathrm{p}=$ 0.000 ). Malaria prevalence among uneducated women was $63 \%$, while among those with primary, secondary and tertiary education, it was $45.3 \%$, about $33 \%$ and $27.3 \%$, respectively.

Pregnant women with low socio-economic status were six times more likely to contract malaria than those with a lower socioeconomic status $(\mathrm{AOR}=6.48, \mathrm{p}=$ 0.011). Our findings are consistent with a study conducted in the DRC by the Messina team [28] who estimated that malaria is a disease of poverty because wealth could protect people against malaria: wealthy families were able to have access to higher levels of awareness, education and prevention of malaria with the same possibility of buying antimalarial drugs that can reduce the rate of malaria infection and thus live in better housing conditions.

The prevalence of malaria was high among pregnant women who lived in houses with non-durable sheet metal materials, i.e. $16.50 \%$ against $4.17 \%$ among 
pregnant women living in houses with durable materials. However, there was no significant association between the type of housing and the occurrence of malaria-illness $(p>0.05)$. These results corroborate those of Dako and allies [9] who found no statistically significant relationship between housing type and participant practice on malaria prevention. On the other hand, the gap is clearly observed with the results of various authors [29] [30] asserting that malaria mainly affects the poor who are likely to live in malaria-endemic areas and in homes with few barriers against mosquitoes. In communities where malaria is endemic, the risk of malaria infection is higher in poorly constructed homes than in well-constructed ones [29]. Similarly, in southern Sri Lanka, the risk of malaria was estimated to be 2.5 times higher among residents of poorly constructed houses compared to those living in houses of good construction [29] [30]. There was a strong association between malaria incidence and house building, and a significantly higher number of resting mosquitoes was observed in poorly constructed homes than in those with good construction.. In our series, the lack of difference significant could be related to the very small number in the sample of people living in houses with sustainable materials. Households composed of 7 to 8 persons had a high prevalence, i.e. $16.33 \%$ compared to $12.77 \%$ of cases for households with 1 to 2 persons. These results corroborate those of some authors. In their study conducted in Ethiopia in 2011, Alemu et al. Found that an average of 5 people lived in a single room and, therefore, the use of prevention measures (especially insecticide-treated mosquito nets) was difficult. It has also been reported that overcrowding may increase the risk of malaria as mosquitoes are attracted by higher concentrations of carbon dioxide and other chemicals in older, overcrowded homes [31].

Most pregnant women surveyed attended the prenatal consultation service, which was $82.21 \%$ compared to $17.79 \%$ of non-users of ANC. The major cause preventing them from following ANC was residing in the field colonies. Pregnant women who did not receive ANC were twice as likely to get malaria as those who followed $(\mathrm{OR}=2.37, \mathrm{p}=0.0049)$. Our findings are consistent with the Obol et al. (2013) study conducted in post-conflict neighbourhoods in Uganda [32) who found that factors favouring the use of ITN included attendance at antenatal clinic services $(\mathrm{AOR}=1.90, \mathrm{p}=0.000)$ and sensitization in health education ( $\mathrm{AOR}=2.12, \mathrm{p}=0.000$ ), while those hindering the use of ITN were the hours taken to reach the Health Centre. $(\mathrm{AOR}=0.64, \mathrm{p}=0.050)$ and being single or divorced $(\mathrm{AOR}=0.22, \mathrm{p}=0.000$ ).

Most pregnant women interviewed in this survey received MS for IPT, which was $76.57 \%$ versus $23.43 \%$ of pregnant women who did not receive it. The non-follow-up of the ANC by a pregnant woman was the first cause (57\%) of non-receipt of MS for IPT. Not receiving MS for IPT was statistically and significantly associated with malaria disease $(\mathrm{AOR}=4.08, \mathrm{p}=0.014)$. Starting the IPT in the third trimester was also a factor exposing the pregnant woman to contracting malaria. These results corroborate those of various authors including 
Tonga et al. [18] who, in their study in Cameroon, reported that participation in prenatal consultations $(\mathrm{p}<0.0001)$ and educational level $(\mathrm{p}=0.018)$ influenced the use of MS for IPT. In the same vein, Ouédraogo et al. [15] also found that the risk of malaria infection was significantly higher in pregnant women whose MS administration for IPT was not supervised.

In this series, the majority of pregnant women surveyed reported using ITNs every night at $85.25 \%$ compared to $23.43 \%$ of pregnant women who did not use them every night. Pregnant women who did not sleep under ITN each night were 17 times more likely to contract malaria than those sleeping every night under the ITN (AOR $=17.39, \mathrm{p}<0.000$ ). Our results are consistent with those of the Fana team [10] who showed in a study conducted in Nigeria that the non-use of insecticide-treated mosquito nets was significantly associated with the increased prevalence of malaria and parasite density. $(\mathrm{X} 2=33.6, \mathrm{p}=0.000)$.

A statistically significant association was observed between not being married and having malaria $(\mathrm{OR}=3.95, \mathrm{p}=0.025)$. Our results are consistent with those of Anchang-Kimbi et al. [17] who observed that being single was associated with an increased risk of contracting malaria compared to married women. Some studies have shown the benefits of being married on the health of individuals [33]. These results could be explained by the fact that marriage could improve health status in that it can ensure economic well-being and the state of health by increasing access to health care. In addition, a spouse can play an important role in monitoring and encouraging healthy behaviors. A husband's support can play a key role in the woman's behavior in favor of maternity attendance at her first ANC.

Pregnant women who supported the cost of malaria interventions were more likely to contract malaria than those who received free malaria control interventions ( $\mathrm{AOR}=3.43, \mathrm{p}=0.0061$ ). Our results corroborate those of some authors [34] [35] who felt that cost is a major barrier to access to health care, especially for the poor. A study in Kenya estimated that direct costs of average cost of Malaria was $7.1 \%$ and $5.9 \%$ of total household expenditures during dry and wet seasons respectively, with richer households being able to cope better [34]. In Ghana, a study found that the high cost of care was perceived as a barrier to accessibility of care and the most significant factor in health decision-making [35]

\section{Conclusion}

The prevalence of malaria in pregnant women in the city of Mwene Ditu was around $14.97 \%$. The risk factors for the occurrence of malaria in the pregnant woman of our series were: not sleeping in ITNs every night, the low socioeconomic level of the couple, agricultural activities, and the facts of not receiving MS for IPT during pregnancy and to support malaria interventions. Efforts should be made by the various stakeholders in the health system to improve environmental conditions and access to malaria control interventions through free access and the correct use of the means of control. Against malaria (TPI and 
MII), women should be made aware of the high attendance of the ANC Service, which is expected to display an adequate organization.

\section{References}

[1] OMS. WHO | World Malaria Report 2015 [Internet]. WHO. 2015. http://www.who.int/malaria/publications/world-malaria-report-2015/en/

[2] Bassey, G., Nyengidiki, T.K. and John, C.T. (2015) Prevalence of Placenta Plasmodium Parasitemia and Pregnancy Outcome in Asymptomatic Patients at Delivery in a University Teaching Hospital in Nigeria. Nigerian Journal of Clinical Practice, 18, 27-32.

[3] Cisse, M., Sangare, I., Lougue, G., Bamba, S., Bayane, D. and Guiguemde, R.T. (2014) Prevalence and Risk Factors for Plasmodium falciparum Malaria in Pregnant Women Attending Antenatal Clinic in Bobo-Dioulasso (Burkina Faso). BMC Infectious Diseases, 14, 631. https://doi.org/10.1186/s12879-014-0631-Z

[4] Mohammed, A.H., Salih, M.M., Elhassan, E.M., Mohmmed, A.A., Elzaki, S.E., El-Sayed, B.B., et al. (2013) Submicroscopic Plasmodium falciparum Malaria and Low Birth Weight in an Area of Unstable Malaria Transmission in Central Sudan. Malaria Journal, 12, 172. https://doi.org/10.1186/1475-2875-12-172

[5] Padonou, G., Le Port, A., Cottrell, G., Guerra, J., Choudat, I., Rachas, A., et al. (2014) Prematurity, Intrauterine Growth Retardation and Low Birth Weight: Risk Factors in a Malaria-Endemic area in Southern Benin. Transactions of The Royal Society of Tropical Medicine and Hygiene, 108, 77-83. https://doi.org/10.1093/trstmh/trt099

[6] Rijken, M.J., De Livera, A.M., Lee, S.J., Boel, M.E., Rungwilailaekhiri, S., Wiladphaingern, J., et al. (2014) Quantifying Low Birth Weight, Preterm Birth and Small-for-Gestational-Age Effects of Malaria in Pregnancy: A Population Cohort Study. PloS One, 9, e100247. https://doi.org/10.1371/journal.pone.0100247

[7] Sohail, M., Shakeel, S., Kumari, S., Bharti, A., Zahid, F., Anwar, S., et al. (2015) Prevalence of Malaria Infection and Risk Factors Associated with Anaemia among Pregnant Women in Semiurban Community of Hazaribag, Jharkhand, India. BioMed Research International, 2015, 740512. http://www.ncbi.nlm.nih.gov/pmc/articles/PMC4691455/

[8] Tandu-Umba, B. and Mbangama, A.M. (2015) Association of Maternal Anemia with Other Risk Factors in Occurrence of Great Obstetrical Syndromes at University Clinics, Kinshasa, DR Congo. BMC Pregnancy and Childbirth, 15, 183. https://doi.org/10.1186/s12884-015-0623-z

[9] Dako-Gyeke, M. and Kofie, H.M. (2015) Factors Influencing Prevention and Control of Malaria among Pregnant Women Resident in Urban Slums, Southern Ghana. African Journal of Reproductive Health, 19, 44-53.

[10] Fana, S.A., Bunza, M.D.A., Anka, S.A., Imam, A.U. and Nataala, S.U. (2015) Prevalence and Risk Factors Associated with Malaria Infection among Pregnant Women in a Semi-Urban Community of North-Western Nigeria. Infectious Diseases of Poverty, 4, 24. https://doi.org/10.1186/s40249-015-0054-0

[11] PNLP (2013) Rapport Annuel sur le Paludisme en 2013. Sécretariat général de la santé, Kinshasa.

[12] EDS-RDC (2014) Deuxième enquête démographique et de santé (EDS-RDC II 2013-2014) [Internet]. ReliefWeb.

http://reliefweb.int/report/democratic-republic-congo/deuxi-me-enqu-te-d-mograp hique-et-de-sant-eds-rdc-ii-2013-2014 
[13] Wumba, RD., Zanga, J., Aloni, M.N., Mbanzulu, K., Kahindo, A., Mandina, M.N., et al. (2015) Interactions between Malaria and HIV Infections in Pregnant Women: A First Report of the Magnitude, Clinical and Laboratory Features, and Predictive Factors in Kinshasa, the Democratic Republic of Congo. Malaria Journal, 14, 82. http://www.ncbi.nlm.nih.gov/pmc/articles/PMC4336768/

[14] MINI SANTE (2015) Plan Stratégique National De Lutte Contre Le Paludisme 2016-2020. PNLP. Sécretariat général de la santé, Kinshasa.

[15] Ouédraogo, C.M.R., Nébié, G., Sawadogo, L., Rouamba, G., Ouédraogo, A. and Lankoandé, J. (2011) Étude des facteurs favorisant la survenue du paludisme à Plasmodium falciparum chez les femmes enceintes dans le district sanitaire de Bogodogo à Ouagadougou, Burkina Faso. Journal de Gynécologie Obstétrique et Biologie de la Reproduction, 40, 529-534. https://doi.org/10.1016/j.jgyn.2011.03.005

[16] Tahita, M.C., Tinto, H., Menten, J., Ouedraogo, J.B., Guiguemde, R.T., van Geertruyden, J.P., Erhart, A. and D’Alessandro, U. (2013) Clinical Signs and Symptoms Cannot Reliably Predict Plasmodium falciparum Malaria Infection in Pregnant Women Living in an Area of High Seasonal Transmission. Malaria Journal, 12, 464. https://doi.org/10.1186/1475-2875-12-464

[17] Anchang-Kimbi, J.K., Nkweti, V.N., Ntonifor, H.N., Apinjoh, T.O., Tata, R.B., Chi, H.F., et al. (2015) Plasmodium falciparum Parasitaemia and Malaria among Pregnant Women at First Clinic Visit in the Mount Cameroon Area. BMC Infectious Diseases, 15, 439. https://doi.org/10.1186/s12879-015-1211-6

[18] Tonga, C., Kimbi, H.K., Anchang-Kimbi, J.K., Nyabeyeu, H.N., Bissemou, Z.B. and Lehman, L.G. (2013) Malaria Risk Factors in Women on Intermittent Preventive Treatment at Delivery and Their Effects on Pregnancy Outcome in Sanaga-Maritime, Cameroon. PLoS ONE, 8, e65876. https://doi.org/10.1371/journal.pone.0065876

[19] Dræbel, T., Kueil, B.G. and Meyrowitsch, D.W. (2013) Prevalence of Malaria and Use of Malaria Risk Reduction Measures among Resettled Pregnant Women in South Sudan. International Health, 5, 211-216. https://doi.org/10.1093/inthealth/iht008

[20] Orish, V.N., Onyeabor, O.S., Boampong, J.N., Aforakwah, R., Nwaefuna, E. and Iriemenam, N.C. (2012) Adolescent Pregnancy and the Risk of Plasmodium falciparum Malaria and Anaemia-A Pilot Study from Sekondi-Takoradi Metropolis, Ghana. Acta Tropica, 123, 244-248. https://doi.org/10.1016/j.actatropica.2012.05.014

[21] Staalsoe, T., Shulman, C.E., Bulmer, J.N., Kawuondo, K., Marsh, K. and Hviid, L. (2004) Variant Surface Antigen-Specific IgG and Protection against Clinical Consequences of Pregnancy-Associated Plasmodium falciparum Malaria. The Lancet, 363, 283-289. https://doi.org/10.1016/S0140-6736(03)15386-X

[22] Jäckle, M.J., Blumentrath, C.G., Zoleko, R.M., Akerey-Diop, D., Mackanga, J.-R., Adegnika, A.A., et al. (2013) Malaria in Pregnancy in Rural Gabon: A Cross-Sectional Survey on the Impact of Seasonality in High-Risk Groups. Malaria Journal, 12, 412. https://doi.org/10.1186/1475-2875-12-412

[23] Ugwu, E.O., Dim, C.C., Uzochukwu, B.S., Iloghalu, E.I. and Ugwu, A.O. (2014) Malaria and Anaemia in Pregnancy: A Cross-Sectional Study of Pregnant Women in Rural Communities of Southeastern Nigeria. International Health, 6, 130-137. https://doi.org/10.1093/inthealth/ihu009

[24] Duffy, P.E. and Fried, M. (1999) Malaria during Pregnancy: Parasites, Antibodies and Chondroitin Sulphate A. Biochemical Society Transactions, 27, 478-482. https://doi.org/10.1042/bst0270478 
[25] Beeson, J.G. and Duffy, P.E. (2005) The Immunology and Pathogenesis of Malaria during Pregnancy. Current Topics in Microbiology and Immunology, 297, 187-227. https://doi.org/10.1007/3-540-29967-X_6

[26] Cot, M. and Deloron, P. (2003) Malaria during Pregnancy: Consequences and Interventional Perspectives. Medecine Tropicale, 63, 369-380.

[27] Bashar, K., Al-Amin, H.M., Reza, M.S., Islam, M. and Asaduzzaman, A.T.U. (2012) Socio-Demographic Factors Influencing Knowledge, Attitude and Practice (KAP) Regarding Malaria in Bangladesh. BMC Public Health, 12, 1084. https://doi.org/10.1186/1471-2458-12-1084

[28] Messina, J.P., Taylor, S.M., Meshnick, S.R., Linke, A.M., Tshefu, A.K., Atua, B., et al. (2011) Population, Behavioural and Environmental Drivers of Malaria Prevalence in the Democratic Republic of Congo. Malaria Journal, 10, 161. https://doi.org/10.1186/1475-2875-10-161

[29] Gamage-Mendis, A.C., Carter, R., Mendis, C., De Zoysa, A.P., Herath, P.R. and Mendis, K.N. (1991) Clustering of Malaria Infections within an Endemic Population: Risk of Malaria Associated with the Type of Housing Construction. The American Journal of Tropical Medicine and Hygiene, 45, 77-85. https://doi.org/10.4269/ajtmh.1991.45.77

[30] Gunawardena, D.M., Wickremasinghe, A.R., Muthuwatta, L., Weerasingha, S., Rajakaruna, J., Senanayaka, T., et al. (1998) Malaria Risk Factors in an Endemic Region of Sri Lanka, and the Impact and Cost Implications of Risk Factor-Based Interventions. The American Journal of Tropical Medicine and Hygiene, 58, 533-542. https://doi.org/10.4269/ajtmh.1998.58.533

[31] Alemu, A., Tsegaye, W., Golassa, L. and Abebe, G. (2011) Urban Malaria and Associated Risk Factors in Jimma Town, South-West Ethiopia. Malaria Journal, 10, 173. https://doi.org/10.1186/1475-2875-10-173

[32] Obol, J.H., Ononge, S. and Orach, C.G. (2013) Utilisation of Insecticide Treated Nets among Pregnant Women in Gulu: A Post Conflict District in Northern Uganda. African Health Sciences, 13, 962-969. https://doi.org/10.4314/ahs.v13i4.15

[33] Wood, R.G., Goesling, B. and Avellar, S. (2007) The Effects of Marriage on Health: A Synthesis of Recent Research Evidence.

https://aspe.hhs.gov/pdf-report/effects-marriage-health-synthesis-recent-research-e vidence

[34] Chuma, J.M., Thiede, M. and Molyneux, C.S. (2006) Rethinking the Economic Costs of Malaria at the Household Level: Evidence from Applying a New Analytical Framework in Rural Kenya. Malaria Journal, 5, 76. https://doi.org/10.1186/1475-2875-5-76

[35] Russell, S. (2008) Demand-Side Factors Affecting Health Seeking Behavior in Ghana GU Journal of Health Sciences, 5, No. 1.

https://blogs.commons.georgetown.edu/journal-of-health-sciences/issues-2/previou s-volumes/vol-5-no-1-april-2008/demand-side-factors-affecting-health-seeking-beh avior-in-ghana/ 